\title{
Evaluation of Seed Quality of Barley Varieties through Controlled Deterioration Test
}

\author{
Aradhana Mishra*, Vikas Kumar, Axma Dutt Sharma and Kalyani Srinivasan \\ National Bureau of Plant Genetic Resources, Pusa Campus, New Delhi, India \\ *Corresponding author
}

\author{
A B S T R A C T
}

Ke y w o r d s
Barley,
Controlled
Deterioration,
Germination,
Seedling vigor,
Viability

\section{Introduction}

Seed deterioration is a natural phenomenon that occurs in all the seeds and leads to the gradual decline in seed viability. Storage temperature and the seed moisture content are the most important determinants of longevity in storage. The rate at which the seed deterioration process takes place depends on the tolerance of seeds to resist degradation which is specific for different species (Gupta and Aneja, 2004). The processing and storage problems are common in tropical countries like India which has hot and humid tropical and subtropical conditions with fluctuations in relative humidity and temperature throughout the year. Seed deterioration is generally characterized by reduced seedling growth, germination capacity and viability (Mohammadi et al., 2011). The rate of seed deterioration varies greatly among the varieties of the same species (Jatoi et al., 2001).

Barley is cultivated as a rabi crop in India, with sowing being undertaken from October to December and harvesting from March to May. India's annual production of barley has been steadily around 1.2-1.5 million tonnes in the recent years. The area under cultivation has also stabilized at around 0.7-0.8 lakh hectares, with a per hectare yield of around $1944 \mathrm{~kg}$. Although barley seeds are long lived, preliminary studies conducted in this 
laboratory revealed that cultivar differences in longevity exist. Establishing the relative longevities of different varieties would facilitate in developing better processing and storage protocols for those which underperform in storage. Seed longevity predictions are made by conducting Accelerated Ageing (AA) tests in many crops seeds. The applications of $\mathrm{CD}$ test to grain crops such as wheat and maize were reported, (Modarresi and Van damme, 2003, Tekrony et al., 2005). Hrstkova et al., (2006) applied this test for comparing the performance of spring and winter barley varieties where $45^{\circ} \mathrm{C}$ and $24 \%$ moisture were recommended but their results indicate that this ageing period is insufficient to bring out the differences between the varieties used by them. The present study was thus aimed to determine the relative longevities of five barley varieties by subjecting them to a modified $\mathrm{CD}$ test allowing longer period of incubation at $45^{\circ} \mathrm{C}$ (48 and 96 hours) as well as raising the moisture content to $20 \%$ and also determine some of the physiological changes occurring in the deteriorated seeds which can serve as indices of seed quality.

\section{Materials and Methods}

The present investigations were undertaken at Division of Germplasm Conservation, National Bureau of Plant Genetic Resources, New Delhi. Five released varieties of barley viz. PL-751, VLB-56, RD-2668, K-713 and DWR-52 procured from National Seeds Corporation, New Delhi were used in present study. The $\mathrm{CD}$ test was conducted at $45^{\circ} \mathrm{C}$ and $20 \% \mathrm{mc}$ for two durations i.e. 48 and 96 hours. For each variety $50 \mathrm{~g}$ seeds of known initial moisture content were placed on moist filter paper and allowed to imbibe to the weight calculated to achieve $20 \% \mathrm{mc}$. The achievement of this weight was determined by periodic weighing. Seeds were then kept at $5^{\circ} \mathrm{C}$ in laminated foil packets for 72 hours to allow moisture equilibration within and among the seeds. Subsamples of $25 \mathrm{~g}$ seeds/treatment were sealed in laminated foil packets and incubated at $45^{\circ} \mathrm{C}$ and removed after 48 and 96 hours (Powell and Matthews, 1981).

The seed lots not subjected to CD served as control. Moisture content of the seeds was determined by high constant temperature oven method (ISTA, 2003).

For germination three replication 50 seeds each were plated in rolled paper and incubated in a seed germinator at $25^{\circ} \mathrm{C}$ and 95\% RH. The seeds were evaluated on the 7th day and normal seedlings were counted for calculation of percent germination (ISTA, 2003).

For the speed of germination, expressed as mean germination time (MGT), 50 seeds in triplicate were plated for germination and counts were taken every day up to 7 th day. The MGT was calculated using the following formula:

Mean germination time $($ MGT $)=\Sigma \mathrm{nd} / \Sigma \mathrm{n}$

Where, $\mathrm{n}=$ number of seeds which germinated on day $\mathrm{d}$

$\mathrm{d}=$ number of days counted from the beginning of germination test.

Three replications of 25 seeds were plated for seedling vigour expressed as seedling length evaluated by measuring separately the length of the root and shoot on the 7th day, and summing up the two.

Seedling vigour index was calculated as the product of germination per cent and seedling length (Abdul-Baki and Anderson, 1973).

The Tetrazolium Test (TZ) for viability was performed for different varieties of barley 
seeds before and after ageing. For this test 10 seeds in three replications were preconditioned by immersing in distilled water at $20^{\circ} \mathrm{C}$ overnight and sectioned longitudinally through the endosperm and embryo and immersed in one percent solution of $\mathrm{TZ}$ at $\mathrm{pH} 7.0$ for $4 \mathrm{hrs}$ in dark at $35^{\circ} \mathrm{C}$. They were then evaluated for the staining pattern using the tetrazolium handbook (Moore, 1973) as the guide. The viability was calculated as percentage of properly stained seeds.

The data was subjected to statistical analysis using Statistical Package for Social Sciences (SPSS). Duncan's Multiple Range Test was followed for comparing treatment means.

\section{Results and Discussion}

\section{Germination per cent}

The changes in seed germination during $\mathrm{CD}$ in five barley cultivars are shown in table 1. Initial germination percentage ranged from 86.66 to $98 \%$ in all control non aged seed lots. This trend changed drastically at 48 hours of $\mathrm{CD}$ where a significant fall in germination percent was observed in PL-751 (53.33\%) and DWR-52 (55.33\%) while K$713(92 \%)$ recorded the highest germination followed by RD-2668 (88\%) and VLB-56 $(84 \%)$ which were on par with each other and also with the respective controls (Fig. 1a). The decrease in germination percent was more pronounced in all the varieties after 96 hours of CD (Fig. 1a). The decrease was drastic in PL-751 (6.66\%) and DWR-52 (4\%), moderate in VLB-56 (53.33\%) while K$713(81.33 \%)$ maintained highest germination percentage.

Five barley cultivars used in the present study showed initially high quality prior to subjecting to $\mathrm{CD}$. Progressive loss in the seed quality attributes occurred with ageing in all varieties but the intervarietal differences were highly significant. Similar observations have been made by others in several other crops viz., pea (Jatoi et al., 2001), wheat (Siddique et al., 2008, Sterlec et al., 2010), pearl millet (Sundereswaran et al., 2009) and rice (Ramanadane and Ponnuswamy, 2004, Ali et al., 2003). This kind of variability in response to natural and AA can be attributed to genetic constitution and the inherent capacity of a cultivar to withstand stresses. The results imply that K-713 had the highest quality in terms of germination and seedling vigour index. The increase in the germination per cent and vigour index after 48 hours of $\mathrm{CD}$ in this variety implies that vigorous metabolic repair leading to invigoration of seeds has taken place due to high moisture content of the seeds as well as the higher temperature to which the seeds were exposed during the $\mathrm{CD}$ test.

\section{Mean germination time}

MGT for control seed lots ranged from 1.29 to 1.80 (Table 1). The lowest MGT was shown by RD-2668 (1.29) while the highest by K-713(1.80). PL-751(1.54), VLB-56 (1.6) and DWR-52 (1.72) were on par. For all the varieties, CD test for 48 hours increased the length of time to reach the germination except for K-713 (1.19) which registered a significant decrease in MGT as compared to control. The maximum MGT was observed for PL-751(3.08) while VLB-56 (2.28) and DWR-52 (2.4) were on par (Table 1, Fig. 1b). As the ageing duration progressed for 96 hours all the varieties recorded a drastic and significant increase in MGT (Fig. 1b). The highest MGT was recorded for DWR-52 (6.73) which was on par of PL-751 (6.66) whereas the lowest MGT was recorded for K713(2.48).

When the seed metabolism is disturbed, initial changes occur resulting in slowing down of germination process leading to late emergence of the seedlings. 
Table.1 Effect of controlled deterioration test on germination percent and MGT

\begin{tabular}{lllllll}
\hline Varieties & \multicolumn{3}{c}{ Germination percent (\%) } & \multicolumn{3}{c}{ Mean Germination Time (Speed) } \\
\cline { 2 - 7 } & Control & CD 48 hrs & CD 96 hrs & Control & CD 48 hrs & CD 96 hrs \\
\hline & & & & & & \\
PL 751 & $86.66 \mathrm{~b}$ & $53.33 \mathrm{~b}$ & $6.66 \mathrm{~cd}$ & $1.54 \mathrm{~b}$ & $3.08 \mathrm{a}$ & $6.66 \mathrm{a}$ \\
VLB 56 & $98.00 \mathrm{a}$ & $84.00 \mathrm{a}$ & $53.33 \mathrm{~b}$ & $1.60 \mathrm{~b}$ & $2.28 \mathrm{~b}$ & $4.07 \mathrm{~b}$ \\
RD 2668 & $94.66 \mathrm{a}$ & $88.00 \mathrm{a}$ & $25.33 \mathrm{c}$ & $1.29 \mathrm{c}$ & $1.65 \mathrm{c}$ & $3.66 \mathrm{bc}$ \\
K 713 & $86.66 \mathrm{~b}$ & $92.00 \mathrm{a}$ & $81.33 \mathrm{a}$ & $1.80 \mathrm{a}$ & $1.19 \mathrm{~d}$ & $2.48 \mathrm{c}$ \\
DWR 52 & $96.00 \mathrm{a}$ & $55.33 \mathrm{~b}$ & $4.00 \mathrm{~d}$ & $1.72 \mathrm{ab}$ & $2.40 \mathrm{~b}$ & $6.73 \mathrm{a}$ \\
\hline
\end{tabular}

Data presented means of three replications.

Data followed by the same letter in a column, do not differ at the $5 \%$ probability level.

Table.2 Effect of controlled deterioration test on seedling vigour and vigour index of five barley varieties

\begin{tabular}{lllllrr}
\hline \multirow{2}{*}{ Varieties } & \multicolumn{2}{c}{ Seedling Vigour } & \multicolumn{3}{c}{ Vigour index } \\
\cline { 2 - 7 } & Control & CD 48 hrs & CD 96 hrs & Control & CD 48 hrs & CD 96 hrs \\
\hline PL 751 & $30.66 \mathrm{~d}$ & $15.32 \mathrm{c}$ & $1.72 \mathrm{~d}$ & $2639.90 \mathrm{c}$ & $821.27 \mathrm{c}$ & $9.70 \mathrm{c}$ \\
VLB 56 & $35.59 \mathrm{bc}$ & $26.00 \mathrm{~b}$ & $10.53 \mathrm{~b}$ & $3486.70 \mathrm{ab}$ & $2181.10 \mathrm{~b}$ & $552.60 \mathrm{~b}$ \\
RD 2668 & $39.90 \mathrm{a}$ & $36.09 \mathrm{a}$ & $5.67 \mathrm{c}$ & $3777.10 \mathrm{a}$ & $3181.30 \mathrm{a}$ & $149.65 \mathrm{c}$ \\
K 713 & $37.21 \mathrm{ab}$ & $37.12 \mathrm{a}$ & $31.76 \mathrm{a}$ & $3222.10 \mathrm{~b}$ & $3421.60 \mathrm{a}$ & $2583.00 \mathrm{a}$ \\
DWR 52 & $33.57 \mathrm{~cd}$ & $13.43 \mathrm{c}$ & $0.44 \mathrm{~d}$ & $3225.10 \mathrm{~b}$ & $751.73 \mathrm{c}$ & $1.77 \mathrm{c}$ \\
\hline
\end{tabular}

Data presented means of three replications.

Data followed by the same letter in a column, do not differ at the 5\% probability level.

Table.3 Effect of controlled deterioration test on seed viability (TZ) of five barley varieties

\begin{tabular}{llcc}
\hline \multirow{2}{*}{ Varieties } & \multicolumn{3}{c}{ Seed Viability $(\%)$} \\
\cline { 2 - 4 } & Control & CD 48 hrs & CD 96 hrs \\
\hline PL 751 & $100 \mathrm{a}$ & $63.33 \mathrm{~b}$ & $11.00 \mathrm{~d}$ \\
VLB 56 & $100 \mathrm{a}$ & $86.66 \mathrm{a}$ & $43.33 \mathrm{~b}$ \\
RD 2668 & $100 \mathrm{a}$ & $86.66 \mathrm{a}$ & $25.33 \mathrm{c}$ \\
K 713 & $100 \mathrm{a}$ & $100 \mathrm{a}$ & $76.66 \mathrm{a}$ \\
DWR 52 & $100 \mathrm{a}$ & $53.33 \mathrm{~b}$ & $6.66 \mathrm{~d}$ \\
\hline
\end{tabular}

Data presented means of three replications.

Data followed by the same letter in a column, do not differ at the $5 \%$ probability level. 
Table.4 Correlation matrix

\begin{tabular}{|l|l|l|l|l|l|}
\hline Parameters & Germination & MGT & $\begin{array}{l}\text { Seedling } \\
\text { vigour }\end{array}$ & Seed viability & $\begin{array}{l}\text { Vigour } \\
\text { index }\end{array}$ \\
\hline Germination & & $-.823^{* *}$ & $.940^{* * *}$ & $.962^{* *}$ & $.915^{* *}$ \\
\hline MGT & & & $-.817^{* * *}$ & $-.849^{* * *}$ & $-.778^{* * *}$ \\
\hline $\begin{array}{l}\text { Seedling } \\
\text { vigour }\end{array}$ & & & & $.949^{* *}$ & $.963^{* *}$ \\
\hline Seed viability & & & & & $.933^{* *}$ \\
\hline Vigour index & & & & & \\
\hline
\end{tabular}

** Correlation is significant at the 0.01 level (2-tailed).

Fig.1 Effect of controlled deterioration test on five barley varieties exposed to different duration of $\mathrm{CD}$ on (a) percent germination, (b) speed (MGT), (c) seedling vigour,

(d) vigour index and (e) viability by $\mathrm{TZ}$

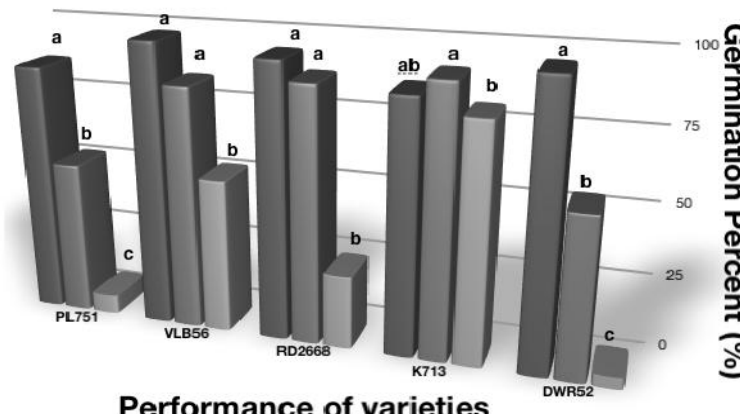

control

CD $48 \mathrm{hrs}$

(a)

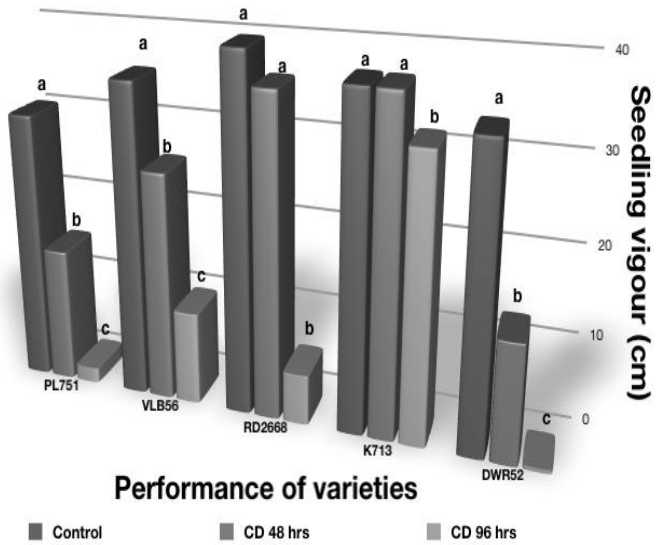

(c)

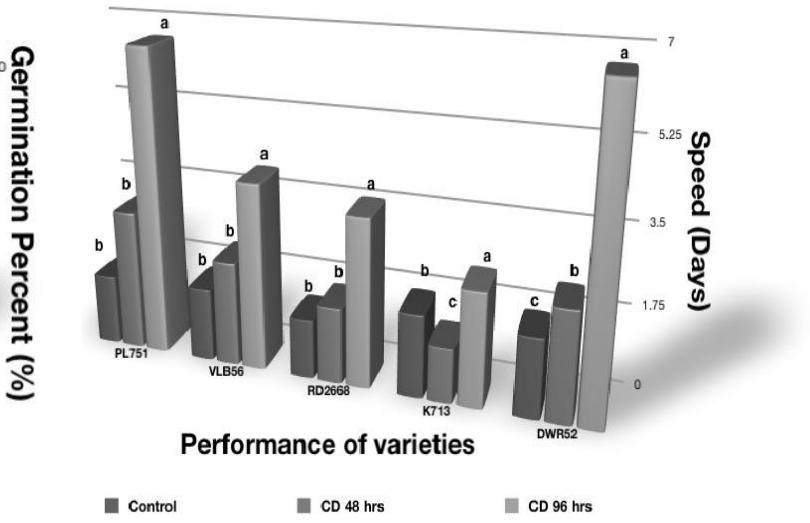

(b)

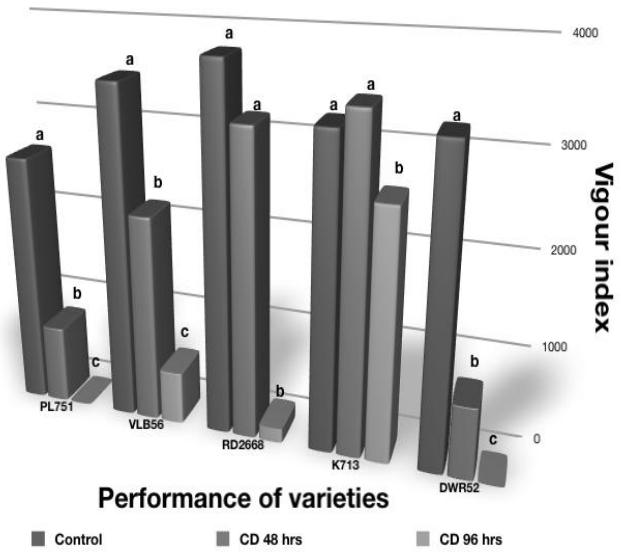

(d) 


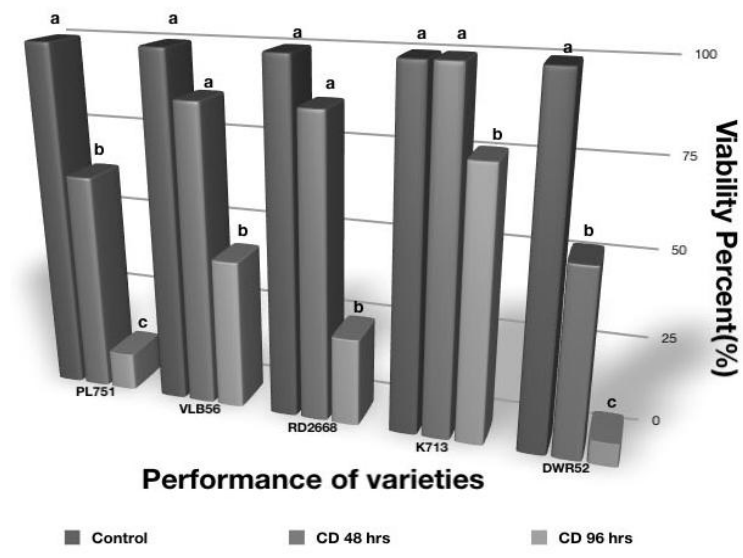

(e)

Lengthening in the mean germination time is the earliest symptom of ageing (Eski and Demir, 2011). Basak et al., 2006 observed in pepper seed lots that decrease in germination percent was associated with an increase in emergence time of seeds. Seed deterioration expresses itself in a reduction in germination rate and uniformity, reduced tolerance to environmental stresses and consequently inferior seedling emergence and growth (Hampton and Tekrony, 1995). Highly significant negative correlation between germination per cent and MGT $(r=-0.823)$ was obtained indicating that germination rate is an important indicator of seed quality loss (Table 4).

\section{Seedling vigour}

Seedling vigour was highly positively correlated with germination per cent $(\mathrm{r}=$ $0.940)$ and highly negatively correlated ( $\mathrm{r}=$ 0.817) with MGT (Table 4). Changes in seedling vigour of different varieties in the control seed lots are given in table 2 . Minimum seedling vigour in the control seeds was observed for PL-751(30.66) followed by DWR-52 (33.57) and maximum in RD-2668 (39.9) followed by K-713(37.21). After 48 hours of $\mathrm{CD}$ minimum seedling vigour was observed in DWR-52 (13.43) which was on par with PL-751 (15.32) and maximum in K713(37.12). After 96 hours of CD all the varieties recorded a significant decrease in seedling vigour as compared to 48 hours aged seed lots (Fig. 1c). Minimum seedling vigour was observed for DWR-52 (0.44) which was on par with PL-751(1.72) while maximum was recorded for K-713(31.76).

Differences in seedling vigour between seed lots are attributed to the rate of germination and seedling growth. There is evidence from comparison of seed lots of onion (Wheeler and Ellis, 1991) and artificially aged seeds of wheat (Guy and Black, 1998) that seeds which germinate earliest have an early start in growth and produce longer seedlings. Iqbal and Smith, 1996 observed a negative impact of seed ageing on root vigour in pea seeds. Seed deterioration during storage resulted in decreased seedling vigour. AA not only affected emergence percentage but also decreased the speed of germination and seedling growth rate resulting in reduced seedling vigour in cucumber seeds which was cultivar dependant (Al-Maskri et al., 2002).

\section{Vigour index}

Table 2 indicates that all the varieties maintained a high vigour index before $C D$ 
test. Minimum vigour index for control seed lots was observed for PL-751 (2639.90) and maximum for RD-2668 (3777.1) which was on par with VLB-56 (3486.7). K-713 (3222.1) and DWR-52 (3225.1) were on par for this parameter. After CD for 48 hours a significant reduction in vigour index was observed in all the varieties except K-713 (3421.60) in which there was increase in the vigour index followed by RD-2668 (3181.3). Minimum vigour index was exhibited by DWR-52 (751.73) which was on par with PL751(821.27). As the CD test duration increased to 96 hours, all the five varieties recorded a significant decline in vigour index as compared to 48 hours aged seed lots (Fig. 1d). K-713 (2583) recorded the maximum vigour index while the minimum was observed for DWR-52 (1.77) followed by PL$751(9.70)$.

Decrease in seedling vigour index due to AA has been reported by Agarwal and Kharlukhi, 1985 in wheat and chickpea seeds. Similar results were observed by Pallavi et al., 2003 in artificially aged sunflower seeds. Ageing induced loss of vigour is due to delayed and non-synchronous germination which in turn is due to altered sequence of metabolic events eventually leading to seed death. Since seedling vigour index is the product of germination and seedling vigour, increase or decrease in any one of the components or both can influence its value greatly. Considerably higher vigour index (2583) exhibited by K-713 even after ageing for 96 hours implies its highest stress tolerance capacity despite the fact that its initial germination and vigour index were not the highest (Fig. 1d).

\section{Seed Viability}

A good correlation was observed between the viability calculated from $\mathrm{TZ}$ test with the germination test $(r=0.962)$ as well as

seedling vigour index $(\mathrm{r}=0.963)$ indicating that this test can be used as a substitute for germination test in case quick results are desired (Table 4). Before treatment all varieties recorded $100 \%$ viability and were hence at par (Table 3). After 48 hours of CD a significant difference was observed between varieties in response to TZ staining. VLB-56 (86.66\%), RD-2668 (86.66\%) and K$713(100 \%)$ were on par and differed significantly with PL-751 (63.33\%) and DWR-52 (53.33\%) (Table 3). After 96 hours of $\mathrm{CD}$ all the varieties recorded a significant decrease in viability as compared to 48 hours aged seed lots (Fig. 1e). The lowest viability was observed for DWR-52 (6.66\%) and maximum viability was observed for K-713 (76.66\%). Similar observations have been reported in aged corn seeds by Bittencourt et al., 2012 and tomato seeds by Santos et al. (2007).

The differences in between the cultivars of barley measured in the present study were highly significant confirming the impact of genotype as well as initial seed quality, especially seed vigour in the final performance of the seed lots. The present study clearly indicates that different varieties of barley deteriorated at different rates when exposed to similar conditions. It is also evident that intial vigour rather than the initial germination per cent is a better indicator of a seed lot's performance when exposed to adverse environmental conditions. Two varieties which had lower vigour than the others deteriorated at a much faster rate than those with higher vigour. The results also indicate the need for special care for processing and storage of varieties with lower vigour potential due to their tendency for accelerated deterioration.

\section{References}


Abdul- Baki, A.A. and Anderson, J.D. 1973. Vigour determination in soybean seed by multiple criteria. Crop Sci. 13: 630633.

Agrawal, P.K. and Kharlukhi, L. 1985. Germination, vigour and leaching of water soluble sugars from seeds of three species during storage under controlled conditions. Seed Res. 13(1): 99- 114.

Ali, M.G., Naylor, R.E.L. and Mattews, S. 2003. The effect of ageing (Using Controlled Deterioration) on the germination at $210 \mathrm{C}$ as an indicator of physiological quality of seed lots of fourteen Bangladeshi Rice (Oryza sativa L.) cultivars. Pak. J. Biol. Sci. 6(10): 910-917.

Al-Maskari, A., Mumtaz Kharr, M., AlMantheriand, O. and Khamis Al-Habs, O.A. 2002. Effect of accelerated ageing on lipid peroxidation, leakage and seedling vigour (RGR) in cucumber (cucumis sativus L.) seeds. Pak. J. Agric. Sci. 39(4): 330-37.

Basak, O., Demir, I., Mavi, K. and Matthews, S. 2006. Controlled deterioration test for predicting seedling emergence and longevity of pepper (Capsicum annum L.) seed lot. Seed Sci. Technol. 34: 701712.

Bittencourt, S.R.M.D., Grzybowski, C.R.D., Panobianco, M. and Vieira, R.D. 2012. Alternative methodology for the accelerated ageing test for corn seeds. Cienc. Rural 42(8): 1360-1365.

Eski, C. and Demir, I. 2011. Shortening the controlled deterioration test for onion. Seed Sci. Technol. 39: 190-198.

Guy, R.A. and Black, M. 1998. Germination related proteins in wheat revealed by different in seed vigour. Seed Sci. Res. 8: 99-111.

Gupta, A. and Aneja, K.R. 2004. Seed deterioration in soybean varieties during storage-physiological attributes. Seed Res. 32: 26-32.
Hampton, J.G. and Tekrony, D.M. 1995. Handbook of vigour test methods. 3rd ed. Int. Seed Testing Asso. Zurich, Switzerland.

Hrstkova, P., Chloupek, O. and Bebarova, J. 2006. Estimation of barley seed vigour with respect to variety and provenance effects. Czech J. Genet. Plant Breed. 42: 44-49.

Iqbal, T.M.T. and Smith, M.L. 1996. Physiological changes of pea seed quality due to ageing. Ann. Bangla Agric., 6: 27-34.

ISTA, 2003. Rule amendments (2003). Seed Sci. Technol. 29 suplement 2, 132pp.

Jatoi, S.A., Afzal, M., Nasim, S. and Anwar, R. 2001. Seed deterioration study in pea, using accelerated ageing techniques. Pakistan J. Biol. Sci. 4 (12): 1490-1494.

Modaressi, R. and Van Damme, P. 2003. Application of the controlled deterioration test to evaluate wheat seed vigour. Seed Sci. Technol. 31: 771-775.

Mohammadi, H., Soltani A, Sadeghipour, H.R. and Zeinali, E. 2011. Effects of seed ageing on subsequent seed reserve utilization and seedling growth in soybean. Int. J. Plant Prod. 5 (1): 65-66.

Moore, R.P. 1973. Tetrazolium staining for assessing seed quality. W. Heydecker (Ed.), Seed Eco. Butterworths, London, UK, pp. 347-366.

Pallavi, M., Kumar, S., Sudheer Dangi, Kuldeep Singh and Vishnuvardhan Reddy, A. 2003. Effect of seed ageing on physiological, biochemical and yield attributes in Sunflower (Helianthus annus L.) cv. Morden Seed Res. 31(2): 161- 168.

Powell, A.A. and Mattehews, S. 1981. Evaluation of controlled deterioration, a new vigour test for small seeded vegetables. Seed Sci. Technol. 9: 633640. 
Ramanadane, T. and Ponnuswamy, A.S. 2004. Ageing and anatomical influence of seed storability in rice (Oryza sativa L.) hybrids and parental lines. Trop. Agri. Res. 16: 37-50.

Santos, M.A.O., Novembre, A.D.L.C., Marcos-Filho, J. 2007. Tetrazolium test to assess viability and vigour of tomato seeds. Seed Sci. Technol. 35: 213-223.

Siddqui, S.U., Ali, A. and Chaudhary, M.F. 2008. Germination behavior of wheat (Triticum aestivum) varieties to artificial ageing under varying temperature and humidity. Pak. J. Bot. 40(3): 1121-1127.

Strelec, I., Komlenic, K.D., Jurkovic, V., Jurkovic, Z. and Ugarcic Hardi, Z. 2010. Quality parameters changes in wheat varieties during storage at four different storage conditions. Agric. Conspec. Sci. 75(3): 105-111.

Sundareswaran, S., Krishnasamy, V., Paramasivam, V. and Ganesan, K.N. 2009. Changes in enzyme activities during seed senescence in pearl millet (Pennisetum glaucum L.) hybrids and their parental lines. Madras Agric. J. 96 (7-12): 300-304.

Tekrony, D.M., Shande, T. and Rucker, M. 2005. Effect of seed shape on corn germination and vigour during warehouse and controlled environmental storage. Seed Sci. Technol. 33: 185-197.

Wheeler, T.R. and Ellis, R.H. 1991. Seed quality, cotyledon elongation at suboptimal temperatures and the yield of onion. Seed Sci. Res. 1: 57-67.

\section{How to cite this article:}

Aradhana Mishra, Kalyani Srinivasan and Axma Dutt Sharma. 2017. Evaluation of Seed Quality of Barley Varieties through Controlled Deterioration Test. Int.J.Curr.Microbiol.App.Sci. 6(6): 3123-3131. doi: https://doi.org/10.20546/ijcmas.2017.606.369 